\title{
Os significados de uma Unidade de Acolhimento transitória para usuários de drogas*
}

\section{Diogo Fiorello Foppa}

(iD) https://orcid.org/0000-0002-2587-8843

Tânia Maris Grigolo²

(D) https://orcid.org/0000-0001-5250-1841

\footnotetext{
* Artigo extraído da dissertação de mestrado "Lançar as amarras ao cais ou viver à deriva? A experiência de uma unidade de acolhimento para usuários de álcool e outras drogas em situação de rua", apresentada à Universidade Federal de Santa Catarina, Florianópolis, SC, Brasil.

${ }^{1}$ Prefeitura de Joinville, Secretaria da Saúde, Joinville, SC, Brasil.

2 Universidade Federal de Santa Catarina, Florianópolis, SC, Brasil.
}

Objetivo: este estudo teve como objetivo compreender os significados da experiência do acolhimento residencial transitório, em uma Unidade de Acolhimento, da perspectiva dos usuários. Método: para tanto, foi realizada uma pesquisa qualitativa utilizando-se da etnografia como estratégia metodológica. O procedimento de coleta de dados envolveu a observação participante com o total de doze usuários e entrevistas abertas com sete destes. A análise foi feita por meio da triangulação dos dados e, para a apresentação, utilizou-se da História Natural da Pesquisa. Resultados: os resultados apontaram que a unidade representa um local de vínculo, com possibilidade do cuidado de si e em liberdade, além da possibilidade da redução do uso de drogas. Conclusão: concluiu-se que se trata de um espaço potente que pode ser utilizado tanto para a saída efetiva quanto apenas temporária das ruas.

Descritores: Saúde Mental; Pessoas em Situação de Rua; Usuários de Drogas; Transtornos Relacionados ao Uso de Substâncias; Antropologia Cultural.

\section{Como citar este artigo}

Foppa DF, Grigolo TM. The implications of a transitional Reception Unit for drug users. SMAD, Rev Eletrônica Saúde Mental Álcool Drog. 2020;16(2):1-9. doi: https://dx.doi.org/10.11606/issn.1806-6976.smad.2020.158015 


\section{The implications of a transitional Reception Unit for drug users}

Objective: the present study aims to understand the implications of the transient residential shelter experience in a Reception Unit from the perspective of the users. Method: in order to do so, qualitative research was carried out using ethnography as a methodological strategy. The data collection procedure involved participant observation with a total of twelve users and open interviews with seven of them. The analysis was conducted through the triangulation of the data and, for the presentation, the Natural History of Research was utilized. Results: the results indicate that the Unit represents an environment of attachment and bonding, with the possibility of looking after oneself, and in freedom, besides the possibility of reducing drug use. Conclusion: it was concluded that this is a powerful and compelling space that can be used both for permanent or only temporary way out of the streets.

Descriptors: Mental Health; Homeless Persons; Drug Users; Substance-Related Disorders; Anthropology Cultural.

\section{Los significados de una Unidad de Acogida de transitoria para los consumidores de drogas}

Objectivo: este estudio tuvo como objetivo comprender los significados de la experiencia de acogida residencial tansitoria em una Unidad de Acogida, desde la perspectiva de los usuarios. Método: para ello, se realizó una investigación cualitativa utilizando la etnografía como estrategia metodológica. El procedimiento de recolección de datos involucró la observación participante con el total de doce usuarios y entrevistas abiertas con siete de ellos. El análisis se hizo por la triangulación de los datos y para la presentación se utilizó la Historia Natural de la Investigación. Resultados: los resultados mostraron que la unidad es un espacio de vínculo, com la posibilidad de cuidado de si mismo, en libertad y, además, con la posibilidad de reducir el uso de drogas. Conclusión: se concluyó que esa unidad es un espacio de gran alcance que se puede utilizar tanto para una salida efectiva o como una salida pasajera de la calle.

Descriptores: Salud Mental; Personas sin Hogar; Consumidores de Drogas; Transtornos Relacionados con Substancias; Antropología Cultural. 


\section{Introdução}

A relação entre o uso de drogas e a população em situação de rua é um fenômeno que já vem sendo estudado nas chamadas sociedades complexas contemporâneas desde o século passado. Nos últimos anos, no Brasil, tal temática ganhou notoriedade ao ser amplamente explorada pelas grandes mídias como uma das principais preocupações relacionadas ao fato de o país sediar dois grandes eventos esportivos mundiais: a Copa do Mundo de futebol, em 2014, e as Olimpíadas, em 2016.

O que é invariavelmente observado nessas grandes repercussões sobre o uso de drogas pela população em situação de rua é a falta de profundidade com que o fenômeno é abordado e a negligência da discussão sobre fatores condicionantes e determinantes. Em geral, aponta-se para o usuário como único e exclusivo responsável pela condição na qual se encontra e/ou a droga em si como o grande mal a ser combatido por ter levado este usuário à situação de rua. Este modelo explicativo é conhecido como paradigma proibicionista médico/jurídico-moral(1).

Estudos recentes, direcionados a compreender o uso de drogas no contexto da situação de rua, têm apontado para a necessidade de superar estes reducionismos que colocam a droga como centro do problema. Um estudo de amplitude nacional, realizado pela Fundação Oswaldo Cruz (FIOCRUZ), com financiamento da Secretaria Nacional de Políticas sobre Drogas do Ministério da Justiça (SENAD/MJ), com a intenção de elucidar respostas para o Estado conhecer mais profundamente os usuários regulares de crack no país, trouxe alguns dados reveladores. O que mais chamou a atenção foram os inúmeros marcadores de exclusão social presentes entre os usuários. A hipótese formulada com os resultados foi que a exclusão social agrava as consequências do uso, mas, além disso, a exclusão e o uso formam um ciclo vicioso que se retroalimenta(2).

Na parte qualitativa da pesquisa, um estudo com aqueles que moram nas ruas revelou uma curiosa relação de continuidade entre a casa e a rua. Muitos relatam ter nascido literalmente nas ruas ou advindo de famílias extremamente pobres, com histórias de privações e violência, tinham a rua como principal espaço de permanência cotidiana, mesmo quando ainda residiam em uma casa( ${ }^{(3)}$.

Na pesquisa de avaliação do programa "De Braços Abertos", da prefeitura da cidade de São Paulo(4), apareceram os mais variados apontamentos dos moradores de rua sobre os fatores que os levaram e os mantêm nesta situação. Conflitos familiares, separação, gravidez inesperada, fracassos profissionais e desemprego são alguns exemplos que marcam a trajetória destas pessoas. Nem sempre, o uso de drogas é mencionado, embora este motivo apareça com frequência. Há uma infinidade de desafios enfrentados relatados por aqueles que moram nas ruas, sendo o consumo problemático de crack e outras drogas apenas mais um deles.

Estes estudos de ampla envergadura evidenciam ainda que "moradia", "residência" e "ter um teto" aparecem com frequência entre as principais reivindicações desta população frente às políticas públicas como uma condição básica para produzir mudanças significativas em suas vidas.

As demandas dos problemas decorrentes do uso de drogas na área da saúde são abordadas pelo campo de conhecimento da Saúde Mental e, especificamente, no Brasil, são tratadas no âmbito da Atenção Psicossocial. Com a Reforma Psiquiátrica Brasileira (RPB), regulamentada pela Lei $10.216^{(5)}$, serviços substitutivos aos hospitais psiquiátricos, principalmente os CAPS, multiplicaram-se como proposta de cuidado em liberdade tanto para pessoas com os chamados transtornos mentais como para pessoas com problemas decorrentes do uso de drogas.

A questão das drogas e dos problemas relacionados ao seu consumo ganhou destaque dentro dessa nova maneira de abordar a Saúde Mental e um espaço privilegiado de cuidado: os CAPS específicos na modalidade Álcool e Drogas, conhecidos como CAPS AD. Se anteriormente estas demandas eram tratadas pela Psiquiatria, dentro da lógica manicomial nos hospitais psiquiátricos ou em comunidades terapêuticas majoritariamente de cunho religioso, em ambos os casos, sob a perspectiva única da abstinência, com a RPB, foi possível expandir as possibilidades de atenção.

Nos dez anos seguintes à publicação da referida lei, após inúmeras experiências, os atores envolvidos com estas políticas identificaram a necessidade de potencializar e ampliar as tecnologias em Atenção Psicossocial, propondo novas práticas e estratégias para a superação dos problemas que a RPB não conseguiu vencer plenamente. Para tanto, em 2011, foi instituída uma Rede de Atenção Psicossocial (RAPS)(6). Esta rede incluiu serviços que já existiam e lançou bases para a criação de outros.

Mediante essa nova configuração, em 2012, surge um novo serviço denominado Unidade de Acolhimento (UA) como um ponto de atenção do componente Residencial de Caráter Transitório da RAPS. Para o Ministério da Saúde, a UA é uma unidade de atenção residencial para pessoas com necessidades decorrentes do uso de crack, álcool e outras drogas por tempo determinado de até seis meses. Deve funcionar como uma residência em período integral, 24 horas e sete dias da semana, de forma articulada com os CAPS AD. Oferece acolhimento voluntário e cuidados contínuos 
para pessoas em situação de vulnerabilidade social e/ou familiar, geralmente em situação de rua, que demandem acompanhamento terapêutico e protetivo(7).

As UAs têm, por finalidade principal, fornecer moradia transitória, mas também oferecer uma atenção mais ampla e integral àqueles mais vulneráveis. Buscam trabalhar fundamentalmente sob o paradigma do cuidado em liberdade, sem a necessidade do afastamento e internações em longo prazo. São guiadas não pelo tratamento baseado na abstinência como única possibilidade, mas com o olhar nas singularidades dos sujeitos e com a redução de danos como norteador das suas práticas.

A lógica de cuidado em Saúde Mental nos CAPS AD e nas UAs baseia-se na ideia de deslocar o tratamento do hospital psiquiátrico e instituições fechadas, locais com ausência de trocas sociais ${ }^{(8)}$, para o território plano do cotidiano. A "doença" como objeto simples e concreto é transformada em objeto complexo e atrelado às múltiplas dimensões da vida. Isso significa atuar necessariamente na transformação da subjetividade e dos modos de viver( ${ }^{(9)}$.

O surgimento das UAs foi resultado da soma entre a necessidade de respostas às demandas relacionadas ao consumo de drogas e uma lacuna de serviços de saúde voltados para pessoas em situação de rua, com problemas decorrentes do uso, que necessitavam de atenção integral.

Este artigo resulta da dissertação de mestrado de um dos autores, que teve como proposta abordar parte desse fenômeno no contexto das Políticas Públicas de Saúde Mental e Atenção Psicossocial, mais especificamente a partir da UA como um dispositivo que se propõe a oferecer uma alternativa de enfrentamento a esta questão tão emergente nas últimas décadas: o uso de drogas pela população em situação de rua.

Objetivou-se, pelo trabalho, partindo de um estudo etnográfico: compreender os significados da experiência do acolhimento residencial transitório, em uma UA, da perspectiva dos usuários.

\section{Método}

O desenho metodológico construído neste estudo foi inspirado nas formulações de Edward MacRae, da Universidade Federal da Bahia (UFBA) ${ }^{(10-11)}$, sobre aspectos metodológicos e abordagens qualitativas no estudo sobre as questões do uso de substâncias psicoativas sob uma perspectiva crítica ao modelo biomédico na área da saúde. Trata-se de um estudo etnográfico, com observação participante. Tal método insere-se no campo da pesquisa de campo qualitativa e descritiva.

O cenário da pesquisa foi uma UA de uma cidade de grande porte da região Sul do Brasil. Os participantes da pesquisa foram moradores desta UA, os quais estavam acolhidos na unidade, e antigos moradores, que já haviam tido a experiência do acolhimento. Participaram do estudo nove moradores que estavam ou passaram pelo acolhimento durante o período da pesquisa de campo e três antigos moradores, em um total de doze. A seleção foi feita a partir do convite e livre aceite e o critério de inclusão foi o de informantes-chave.

O principal procedimento de coleta de dados constituiu-se da própria observação participante. Durante um período de seis meses, de janeiro a junho de 2018, foi feita uma imersão sistemática diária no campo, das segundas às sextas-feiras, das $12 \mathrm{~h}$ às $18 \mathrm{~h}$. Tal procedimento teve como instrumento de registro o Diário de Campo. Como complemento, foram realizadas entrevistas abertas, conduzidas por um roteiro indicativo de alguns itens a explorar, com as quais se procuraram investigar, de forma aprofundada, informações específicas. Foi realizado um total de sete entrevistas, quatro com moradores e três com antigos moradores. Utilizou-se do princípio da saturação para delimitar esta amostragem.

O modelo de análise, por tratar de assuntos cuja finalidade é descrevê-los e classificá-los em categorias qualitativas, foi feito por meio da triangulação dos dados obtidos pelos diferentes meios de observação e registro. Foram buscados discursos, práticas e representações constitutivas de uma cultura em comum compartilhada, procurando não criar grupos falsamente homogêneos, mas apreender unidades de funcionamento, começando com a análise e a compreensão de detalhes interrelacionados, que se identificam em padrões e processos cada vez mais amplos, tendo como parâmetros categorias de análise.

A apresentação dos dados etnográficos foi feita por meio da História Natural da Pesquisa(10). A mesma envolve a descrição explícita e sistemática de todos os elementos e passos do processo, com narração histórica e contextualizada.

O estudo está em consonância com o proposto nas diretrizes estabelecidas pela resolução no 466, de 2012, do Conselho Nacional de Saúde(12). Também foram observados os dispositivos da Lei 10.2016. O projeto foi submetido ao Comitê de Ética em Pesquisa com Seres Humanos da Universidade, com parecer favorável no 2.646.531. Os participantes que aceitaram participar do estudo assinaram o Termo de Consentimento Livre e Esclarecido (TCLE).

\section{Resultados e discussão}

O universo do que se conhece por "pessoas em situação de rua" não é homogêneo, ainda que estes compartilhem de certas características em comum. Dentre os mesmos, existem os que acessam diretamente os serviços públicos e os que não os acessam. Os 
que acessam dividem-se entre os que o fazem eventualmente, ou emergencialmente, como forma de suprir alguma necessidade básica de sobrevivência, e os que o fazem com determinada frequência e buscam se vincular principalmente com os serviços especialmente voltados para essa população.

Essa vinculação pode exercer duas funções distintas, não necessariamente excludentes uma da outra. A primeira é a manutenção da vida nômade por meio do acesso a banhos, roupas limpas, cobertores, alimentação, confecção de documentos, entre outros. A segunda é o auxílio para fixar-se e sair da situação de rua por meio do resgate dos vínculos familiares, recolocação no mercado de trabalho, qualificação profissional, cuidados de saúde e redução do uso de drogas.

As pessoas em situação de rua que chegam na UA são, quase que exclusivamente, aquelas que compõem este último grupo, dos frequentadores mais ou menos assíduos dos serviços públicos. Isso se dá pela especificidade da unidade, que é servir de suporte residencial transitório para quem está em tratamento no CAPS AD, ou seja, que buscou voluntariamente algum auxílio.

\section{Os que chegam e os que ficam}

A partir dos discursos dos informantes-chave entrevistados, foi possível identificar categorias de "tipos" de moradores da UA. Trata-se, a princípio, de como os próprios moradores identificam uns aos outros dentro dos seus juízos de valor e os comparam a si mesmos. São eles: 1 - os que desejam se fixar. Isso implica um processo de mudança nos modos de vida, inclui diminuir o uso de drogas, procurar um trabalho formal, resgatar e compartilhar as normas sociais que foram, em parte, abandonadas; 2 - aqueles que querem apenas sair temporariamente das ruas. Em geral, não articulam movimentos de mudança seja no sentido de trabalhar suas questões de saúde mental, buscar resgatar os vínculos afetivos, se qualificar profissionalmente, acessar as redes intersetoriais ou gerar algum tipo de renda; 3 - o terceiro "tipo" são aqueles que, em geral, manifestam desejo e executam algumas ações no sentido da mudança, mas possuem alguma característica específica: apresentam maiores limitações quanto à execução de seus projetos pessoais, seja pela significativa dependência de alguma substância, um grave sofrimento mental associado, déficits cognitivos e a dificuldade de se adaptar a um modelo de residência.

A decisão entre fixar-se em uma residência ou continuar à deriva nas ruas geralmente envolve uma avaliação de custo-benefício. Em geral, os empregos, carro-chefe para a efetiva saída das ruas, aos quais essa população tem acesso (quando tem), são pessimamente remunerados, exigem uma rígida disciplina e esforço físico acima da média. Com frequência, os usuários acabam avaliando que é mais vantajoso manter a vida nômade na qual se consegue o mínimo para sobreviver, apesar de todo sofrimento, do que trabalhar exaustivamente para obter pequenos confortos em uma residência.

Ouvem-se exemplos de moradores que iniciaram trabalhos formais nas grandes indústrias, os chamados "chão de fábrica", e acabaram não dando conta por não conseguirem cumprir o horário rígido, frustraram-se com facilidade frente aos inúmeros desafios e, principalmente, em relação à baixa remuneração. Em contraponto, a vida nas ruas parece menos onerosa sob a avaliação de muitos: Tem gente que consegue as coisas muito fácil na rua, pessoa que tem lábia, chega em um e consegue comida, dinheiro, tudo, consegue tudo fácil, e tem gente que se adapta na rua, tem gente que cai em qualquer canto e dorme, no meu caso, eu não conseguia dormir na rua (...) tem os que gostam dessa vida, a maioria dos restaurantes dá a comida, aí, o cara tem a lábia e pensa: "Por que vou trabalhar?". (E3)

Ao entrar na UA, os sentidos vão sendo produzidos e transformados conforme as situações vão sendo experimentadas. Esta relação custo-benefício também é constantemente reavaliada. Entra em jogo a dificuldade do processo de transição do universo livre das ruas e com poucas regras, para um ambiente onde as relações geram conflitos e frustrações, mas que, por outro lado, oferece uma série de transformações positivas.

\section{Cuidando de si}

Independentemente do desejo por grandes mudanças e de se fixar em um estilo de vida permeado pelos vínculos familiares e trabalhistas, a UA possibilita o cuidado consigo. A partir do momento em que as necessidades básicas, como a alimentação, sono, segurança e higiene, começam a ser supridas, diferentes graus de autocuidado são evidenciados. Os cuidados com o próprio corpo, o retorno ao estudo formal ou a busca por qualificação profissional e o resgate dos vínculos são os movimentos de cuidar de si mais observados entre os moradores.

Nas primeiras semanas de acolhimento na unidade, são perceptíveis as mudanças no aspecto visual. Eles perdem a aparência emagrecida característica dos usuários pesados de drogas, observa-se um cuidado maior com a frequência dos banhos, em barbear-se e cortar os cabelos, em lavar as roupas e na imagem em geral. Um ponto que chama a atenção é a grande procura dos moradores por atendimento odontológico. Tal preocupação dá-se mais por questões estéticas do que de saúde propriamente dita. Revela-se um ponto simbólico de transição do abandono do próprio cuidado nas ruas para um olhar voltado para si, inclusive, com questões estéticas outrora negligenciadas. 
Os cuidados com a saúde são mediados pela equipe, principalmente, com a atenção básica. Esta é muito pouco acessada por essa população, e essa aproximação vem sendo estreitada, evidenciando-se frutíferos resultados. É uma população que, pelas condições de vida, apresenta elevados níveis de problemas de saúde e pouca atenção recebida. Não é incomum, ao entrar na UA, que se inicie uma verdadeira maratona de consultas, exames, cirurgias e vários outros procedimentos de saúde.

O investimento feito pelo serviço e o olhar atento às questões de saúde são frequentemente lembrados quando perguntado diretamente aos moradores o que mais Ihes marca quando pensam em suas trajetórias na UA. Um dos moradores ressalta o itinerário de cuidado com sua saúde que iniciou após o processo de acolhida na unidade. Apesar de ainda não ter conseguido um trabalho, graças a Deus, eu conquistei um monte de coisa aqui na casa, tô cuidando da minha saúde, voltei a tomar os remédios, tô fazendo um monte de exames pra ver se agora eu finalmente descubro o que tenho. Antes, eu quase não ia no médico, agora, tô com a agenda cheia, as meninas lá do PAM já me conhecem de tanto que eu vou lá. (E5)

Uma outra maneira de cuidar de si, que emerge das falas e se observa nos movimentos dos moradores, é o reingresso na educação formal. Quando o assunto é agir sobre o próprio destino, a educação é vista como uma das possibilidades de "mudar de vida". Um deles atribui à UA o papel de mediadora de seu processo de saída das ruas e afirma que, durante sua estada na unidade, viu no retorno ao estudo o melhor modo de dar um novo rumo para a sua vida. (...) naquela época, a primeira vez que eu fiquei aqui, eu tava muito "deprimidão" e acho que entenderam isso, não ficaram me cobrando tanto pra eu ir procurar emprego, falaram que era bom eu terminar o Ensino Médio, que isso ia me ajudar. E, realmente, se eu peguei emprego, foi porque eu tava com o estudo terminado, terminado não porque eu tenho a vontade de um (curso) técnico e até uma faculdade. Mas o segundo grau já é um bom começo. (E1)

Um morador que estava na casa há pouco mais de quatro meses já havia feito três cursos profissionalizantes: um de elétrica, um de hidráulica e um complementar de NR35, que habilita para o trabalho em altura. Os dois primeiros fazem parte de projetos conjuntos com a Secretaria de Assistência Social; o último foi uma cortesia de um dos seus professores que também ministra aulas em outra escola.

Com o passar do tempo, após a entrada na UA, há um movimento pelo estreitamento ou o resgate do contato com pessoas com quem o agora morador ainda possui algum vínculo afetivo, geralmente, familiares. Os vínculos com o núcleo familiar, ou seja, com aqueles com quem se dividia a casa, como o cônjuge, filhos, pai e mãe, em geral, encontravam-se rompidos ou muito desgastados, sendo esse rompimento, em diversas situações, o principal desencadeador da ida para as ruas. Os familiares, mesmo aqueles que não desejam reatar os vínculos como um dia já foram, de maneira geral, correspondem positivamente à reaproximação, uma vez que manifestam expectativas de que o familiar abandone a vida à deriva e o uso de drogas.

Além da família, outros vínculos são estabelecidos nesse processo. As igrejas, principalmente evangélicas, exercem um papel ativo no estabelecimento de relações afetivas e de suporte com esse público mais vulnerável. O exemplo do curso que Moreno ganhou de cortesia do professor que Ihe ensinava hidráulica, e também era um "irmão da igreja", ilustra essa relação. O professor apadrinhou o usuário e inseriu-o em suas relações comunitárias, uma vez que Moreno não tinha mais contato com a família.

\section{O cuidado em liberdade}

Os itinerários de vida das pessoas em situação de rua são marcados pelos inúmeros contatos com serviços e instituições que oferecem algum suporte para que possam "abandonar o mundo das drogas". Essas instituições têm como função a tentativa de propor uma nova norma de vida para esses sujeitos, tirando-os da situação de rua e impondo a abstinência total de qualquer droga como meio para mudar sua condição(13). Entre comunidades terapêuticas, hospitais psiquiátricos e clínicas de tratamento, existem diversos serviços que se dedicam a essa missão.

Dentre as variações existentes, o isolamento do sujeito de seu contexto social e a abstinência são os imperativos que norteiam as práticas de tais serviços, partindo de paradigmas diferentes dos das UAs. As comparações com outros modelos de tratamento apareceram em inúmeras situações, por diferentes usuários, refletindo o caráter inovador e contrahegemônico de um cuidado residencial com portas abertas. Cara, eu já perdi as contas de quantas clínicas já fiquei; você fica lá nove meses, é bom?; é, às vezes, é em fazenda, que, por um lado, é bom que o cara fica lá isolado, tem bicho pra cuidar, mas também tem que trabalhar muito e rezar bastante também, coisa que eu já não gostava. Até aí, tudo bem, o cara aguenta. Mas, e daí, quando sai? As loucuras do cara saem com ele, a sociedade não mudou e a vontade de usar vem grande. O que é a primeira coisa que o cara faz quando sai de lá? Vai usar! (E3)

Na UA, a movimentação é constante, os moradores vão ao CAPS AD, à escola, procurar emprego, passear, visitar amigos, família, acessam os serviços de saúde, eventualmente, saem para usar algum tipo de droga e uma infinidade de outras tarefas cotidianas, sem que isso afete, de forma substancial, o que se entende por tratamento. Pelo contrário, funciona como uma espécie de laboratório para, quando acontece algo de 
desestabilizador, seja pelo uso de drogas ou não, que o usuário tenha suporte para lidar com o que está ocorrendo ali mesmo no momento.

Em algumas situações, pôde-se observar como é trabalhado pela equipe, nas relações cotidianas, a exposição ao uso de drogas. Esta fala parte de uma intervenção da assistente social com um dos moradores, a qual se teve a oportunidade de presenciar, ilustrando a visão do ponto de vista do usuário sobre o cuidado em liberdade. (...) vou te contar uma coisa: naquela vez, lá no começo, quando eu entrei aqui, que eu não consegui me controlar e tinha usado, eu vim direto pra pegar minhas coisas e ir embora porque pensei: "Eu saí sem avisar, enchi a cara de droga, os caras vão me mandá embora!". Aí, eu fiquei surpreso quando eu cheguei e a senhora falou que era pra eu entrar, tomar um banho e descansar. Nos outros lugar que eu fiquei, "é tchau", vacilou, não tem volta. Pensei comigo: "Eu faço cagada e os caras ainda me tratam bem". Aí que eu comecei a entender qual era a coisa por trás, qual que é o plano de vocês, e hoje eu posso dizer que dá certo. (E4)

O cuidado em liberdade desperta uma certa estranheza, mas, ao mesmo tempo, um aumento no senso de responsabilidade. Não há um controle, por parte da equipe, sobre o que é feito da porta para fora, entretanto, percebe-se uma autovigilância maior para manter aquilo que é contratualizado entre o grupo. Existe uma cobrança entre o próprio grupo de moradores sobre a responsabilidade e o comprometimento com os horários de saída e chegada que, em geral, são discutidos coletivamente. Esse tipo de comprometimento com os próprios pares acaba exercendo uma série de funções autorregulatórias: não passar a noite fora sem avisar, não chegar sob efeito de drogas e preservar a segurança do local.

\section{A função das drogas}

O tema das drogas não só perpassa o acolhimento na UA, mas, além de tudo, é estruturante na razão de ser deste dispositivo. Dentro da perspectiva da Atenção Psicossocial, os serviços de saúde não têm como vocação ofertar tratamento com foco exclusivo na interrupção total e imediata do uso de drogas, mas oportunizar ferramentas para que os usuários criem ou ampliem suas habilidades de gerenciar suas próprias vidas com o mínimo de danos possíveis causados pelo consumo de drogas, seja interrompendo o uso ou não.

O que se constatou com o estudo é que, em geral, há um esforço para o abandono do uso, principalmente, o crack e o álcool. Entretanto, percebe-se uma especificidade em relação à maconha e uma tendência à manutenção do seu uso em muitos casos por esta não ser considerada uma substância perigosa ou prejudicial.

Existem pequenas particularidades ligadas ao uso de cada substância em específico. O uso do crack está bastante relacionado ao contexto das ruas pelos usuários e é referido nas falas a seguir. (...) aqui, eu me sinto protegido. (E7); Não sinto mais tanta vontade de usar porque aqui tenho com o que me ocupar, com quem conversar (...). (E1); Esse uso tem relação com os trajetos e itinerários que os usuários percorriam. (...) esse era o horário (ao anoitecer) que eu começava a correria, saía por aí mangueando para levantar o maior troco possível para me internar na pedra. (E3)

Os usuários exclusivos de álcool demonstraram maior dificuldade em interromper o uso por longos períodos, se comparados com os usuários exclusivos de crack. As tentativas de explicar a maior dificuldade em reduzir ou deixar o uso de álcool, comparado às outras drogas, giram em torno da legalidade do mesmo e do papel socializador nos diferentes contextos e camadas sociais, como, por exemplo, nesta fala trazida após um intenso uso logo depois de receber o seu primeiro salário. (...) eu tava feliz, tinha recebido (...), fico me perguntando por que todo mundo pode tomar uma cervejinha, confraternizar, e eu não? Sentei no bar para conversar, tomar uma e, quando vi, já era, você já sabe o resto da história. (E2)

Identificou-se que a especificidade da manutenção do uso da maconha está ligada a duas questões centrais: primeiro que, por ser uma droga que é geralmente avaliada com um baixo potencial de causar danos, é utilizada amplamente com fins recreativos sem a preocupação de que seu uso desestabilize o restante dos seus projetos. Segundo, a maconha é vista como um "redutor de danos". É comum o seu uso para aliviar a fissura e os sintomas de ansiedade, insônia e falta de apetite decorrentes da abstinência do crack ou álcool.

De modo geral, o acolhimento residencial produz uma significativa redução de danos e do consumo em si, provavelmente amparada pelas necessidades básicas supridas, como a alimentação adequada, banho quente, sono na quantidade e em local adequado e interação humana. Muitas daquelas funções que as drogas tinham nas ruas, como sociabilidade, proteção contra o medo e o frio e desinibição, já não fazem mais sentido quando se está acolhido.

A casa acaba exercendo um papel de local de proteção. Não é necessariamente, ou apenas, o espaço físico que "protege" os moradores, pois muitos destes já faziam um uso pesado antes de ir para as ruas quando residiam em casas. Mas muito mais um desejo de cumprir com a expectativa do outro, sejam os profissionais ou os colegas moradores, ou seja, também, o espaço simbólico de proteção, cuidado e compromisso firmado.

\section{Formação de vínculos}

O vínculo acaba sendo a principal ferramenta para trabalhar as mais diversas demandas que surgem no cotidiano da unidade. Destacadamente, as dificuldades em lidar com as frustrações aparecem como o maior 
impeditivo para que se avance sobre os seus projetos singulares, e a equipe depara-se constantemente com a necessidade de abordar tal demanda.

Alguns moradores captam como a dinâmica funciona de forma diferente na relação com a equipe em comparação com a relação familiar. Tanto na casa da minha mãe como na rua eu não sabia lidar com a frustração, corria para o crack, me afundava. Aqui, também tinha a frustração, claro, mas aí eu tinha a quem recorrer, tinha vocês, conversava com um, conversava com outro, o pessoal me ajudou muito aqui, vocês, eu digo. Eu procurava direto. (E2); (...) consegui aprender um pouco a controlar minha frustração, a lidar com ela. Na minha casa, você sabe, é diferente, ninguém entendia quando eu tava puto, tava chateado (...) não é por falta de amor, acho que, na verdade, era até excesso, mas não funcionava. Aqui, me ouviam e me devolviam falando a real, de forma educada, claro, mas falavam a situação. (E5)

Estudos na área da saúde evidenciam o papel positivo que o vínculo entre profissional da saúde e paciente desempenha no processo de tratamento e até mesmo na cura de doenças ${ }^{(14-15)}$. Na Saúde Mental, em que as tecnologias de cuidado são fundamentalmente tecnologias leves, baseadas nas relações humanas, o papel do vínculo é ainda mais determinante. A UA é um local onde ele existe por excelência devido à característica residencial e aos profundos contatos sociais que proporciona, além da possibilidade concreta de se estabelecerem vínculos duradouros e, com isso, transformar a realidade dos usuários.

\section{Considerações finais}

Uma imersão etnográfica no dia a dia da unidade permitiu compreender o dispositivo como potencial em produzir mudanças nas histórias de vida, dado, principalmente, ao vínculo enquanto tecnologia de cuidado. Observou-se, ainda, que o acolhimento contribuiu, também, enquanto condicionante na decisão de como guiar e organizar seus percursos de vida a partir de então. Os significados atribuídos ao acolhimento são múltiplos, e a pesquisa evidenciou o cuidado de si, a possibilidade do cuidado em liberdade e a diminuição ou interrupção do uso de drogas, a UA como espaço de proteção e segurança, que proporciona a ampliação das redes e das relações sociais e a saída das ruas e fixação.

Os participantes da pesquisa apresentam um ritmo próprio na maneira de conduzir suas vidas, na maioria das vezes, recusando-se a seguir os códigos sociais ditados pela sociedade e replicados na micropolítica dos serviços de saúde. No caso da UA, o objetivo de que o serviço seja um meio para que os usuários deixem a errância foi muitas vezes subvertido e outros significados foram sendo construídos. No serviço, é vista, também, uma possibilidade de apenas "dar um tempo" da vida nas ruas.
A UA é um potente ponto de atenção e dispositivo de cuidado existente dentro da RAPS, está em consonância e harmonia com os pressupostos da RPB e com a Política de Atenção Psicossocial. Apresenta-se como uma alternativa de cuidado ao modelo manicomial e asilar. Por trabalhar com a perspectiva de redução de danos e na lógica de cuidado em saúde, pressupõe respeito à singularidade dos sujeitos, aos direitos humanos e à cidadania.

Apesar disso, existem diferentes obstáculos que necessitam ser superados para uma adequada efetivação e fortalecimento deste modelo de ponto de atenção de consolidar-se como opção primeira na escolha de serviços de caráter residencial transitório pelos municípios, gestores e pelos próprios usuários. No município pesquisado, a UA mostra-se como um rico potencializador da rede, com possibilidades latentes que demandam melhorias e investimentos para ser florescida.

Os resultados e apontamentos levantados por esta pesquisa foram levados aos gestores municipais, às equipes e aos usuários do serviço como devolutiva.

\section{Referências}

1. Trad SNS, Trad LAB, Romani O. Contribuições das ciências sociais ao estudo sobre o uso de drogas e o diálogo com a produção nacional contemporânea. In: Jorge MSB. (org.). Olhares plurais sobre o fenômeno do crack. Fortaleza: EdUECE; 2015. p. 26-70.

2. Garcia L. Apresentação Senad/MJ. In: Souza J. Crack e exclusão social. Brasília: Ministério da justiça e Cidadania, Secretaria Nacional de Política sobre Drogas; 2016. p.11-16.

3. Mayora M. O crack e a rua. In: Souza J. Crack e exclusão social. Brasília: Ministério da justiça e Cidadania, Secretaria Nacional de Política sobre Drogas; 2016. p. 137-161.

4. Rui TC, Fiore M, Tófoli LF. Pesquisa preliminar de avaliação do Programa 'De Braços Abertos' [Internet]. São Paulo (SP): Plataforma Brasileira de Política de Drogas (PBPD)/ Instituto Brasileiro de Ciências Criminais (IBCCRIM); 2016. 122p. [Acesso $10 \mathrm{abr}$ 2019]. Disponível em: http://pbpd.org.br/wp-content/ uploads/2016/12/Pesquisa-De-Bra\%C3\%A7osAbertos-1-2.pdf

5. Ministério da Saúde (BR). Lei n. 10.216, de 6 de abril de 2001. Dispõe sobre a proteção e os direitos das pessoas portadoras de transtornos mentais e redireciona o modelo assistencial em saúde mental. Brasília: MS; 2001.

6. Ministério da Saúde (BR). Portaria n. 3.088, de 23 de dezembro de 2011. Institui a Rede de Atenção Psicossocial para pessoas com sofrimento ou transtorno mental e com necessidades decorrentes do uso de crack, 
álcool e outras drogas, no âmbito do Sistema Único de Saúde. Brasília: MS; 2011.

7. Ministério da Saúde (BR). Portaria n. 121, de 25 de janeiro de 2012. Institui a Unidade de Acolhimento para pessoas com necessidades decorrentes do uso de Crack, Álcool e Outras Drogas (Unidade de Acolhimento), no componente de atenção residencial de caráter transitório da Rede de Atenção Psicossocial. Brasília: MS; 2012.

8. Kinoshita RT. Contratualidade e reabilitação psicossocial. In: Pitta $A$, organizador. Reabilitação psicossocial no Brasil. São Paulo: Hucitec; 2016. p. 55-59. 9. Venturini E. A desinstitucionalização: limites e possibilidades. Rev Bras Crescimento Desenvolv Hum. 2010;20(1):138-51. doi: https://doi.org/10.7322/ jhgd.19953

10. MacRae E. Abordagens qualitativas na compreensão do uso de psicoativos. In: Tavarez LA, organizador. As drogas na contemporaneidade: perspectivas clínicas e culturais. Salvador: Edufba; 2004. p. 27-48.

11. MacRae E, Vidal SS. A Resolução 196/96 e a imposição do modelo biomédico na pesquisa social: dilemas éticos e metodológicos do antropólogo pesquisando o uso de substâncias psicoativas. Rev Antropol. 2006;49(2):645-66. doi: 10.1590/ S0034-77012006000200005

12. Ministério da Saúde (BR). Resolução n.466, de 12 de dezembro de 2012. Aprovam diretrizes e normas regulamentadoras de pesquisas envolvendo seres humanos. Brasília: MS; 2012.

13. Alves YA. Jamais fomos zumbis: contexto social e craqueiros na cidade de São Paulo. Salvador: Edufba; 2017. 350 p.

14. Brunello MEF, Ponce MAS, Assis EG, Andrade RLP, Scatena LM, Palha PF, et al. O vínculo na atenção à saúde: revisão sistematizada na literatura, Brasil (1998-2007). Acta Paul Enferm. 2010;23(1):131-5. doi: 10.1590/S0103-21002010000100021

15. Barbosa MIS, Bosi MLM. Vínculo: um conceito problemático no campo da Saúde Coletiva. Physis. 2017;27(4):1003-22. doi: 10.1590/ s0103-73312017000400008

\section{Contribuição dos autores}

Concepção e planejamento do estudo: Diogo Fiorello Foppa, Tânia Maris Grigolo. Obtenção dos dados: Diogo Fiorello Foppa. Análise e interpretação dos dados: Diogo Fiorello Foppa, Tânia Maris Grigolo. Preparação e redação do manuscrito: Diogo Fiorello Foppa. Revisão crítica do manuscrito: Tânia Maris Grigolo.

Todos os autores aprovaram a versão final do manuscrito. Conflito de interesse: os autores declaram não haver conflito de interesse. 